\title{
Del libro rojo de Winston al Black Mirror. dispositivos de control en la sociedad de la vigilancia
}

María Rocío Arango ${ }^{1}$

Recibido: 29/01/2019

Aprobado por pares: 07/03/2019
Enviado a pares: 29/01/2019

Aceptado: 26/03/2019

DOI: 10.5294/pacla.2020.23.1.3

Para citar este artículo / to reference this article / para citar este artigo Arango, M. R. (2020). Del libro rojo de Winston al Black Mirror. dispositivos de control en la sociedad de la vigilancia. Palabra Clave, 23(1), e2313. D0I: https://doi.org/10.5294/ pacla.2020.23.1.3

\section{Resumen}

Este artículo presenta una reflexión teórica respecto de la vigilancia como dispositivo garante del orden social. Afirma que el nuevo ensamblaje de vigilancia que se inaugura con la puesta en marcha de internet tiende hacia el control total de la vida mediante la coacción directa y violenta, o el entretenimiento y la diversión. Se ocupa de tres dispositivos de vigilancia significativos, a saber, el panóptico como punto de encuentro entre la sociedad disciplinaria que ya no somos y la sociedad de vigilancia que comenzamos a ser, el sinóptico o el control y la vigilancia de la vida privada, íntima y emocional, y la analítica predictiva o la preferencia por la búsqueda de correlaciones entre millones de datos disponibles sobre la cotidianidad que pretende, si no explicar la causa de los fenómenos, sí buscar nuevas formas de coacción, así como de las razones por las cuales el funcionamiento de estos dispositivos hace de la sociedad contemporánea una sociedad de la vigilancia. Al exponer las características propias de cada uno de estos dispositivos, el artículo pretende mostrar el papel de la vigilancia en la regulación

1 https://orcid.org/0000-0002-0068-9843. Universidad Eafit, Colombia. marango@eafit.edu.co 
de la vida social. Por último, plantea reflexiones a propósito de la pérdida de libertad que trae consigo la ganancia en confianza y seguridad producto del sometimiento voluntario o, en algunos casos, irreflexivo a nuevos modos de control sutiles y en apariencia inocentes, tales como la pertenencia a redes sociales, la suscripción electrónica a distintos servicios o la mera consulta en alguno de los buscadores más populares.

\section{Palabras clave (Fuente: tesauro de la Unesco)}

Sociedad de vigilancia; panóptico; sinóptico; analítica predictiva; dispositivos de control. 


\section{From Winston's Red Book to the Black Mirror: Control Devices in the Surveillance Society}

\section{Abstract}

This article presents a theoretical reflection on surveillance as a guarantor of social order. It states that the new surveillance assembly that started with the launch of the Internet tends towards absolute control of life through direct and violent coercion, or entertainment and fun. It deals with three significant surveillance devices, namely, panoptic as a meeting point between the disciplinary society we no longer are and the surveillance society we are becoming; synoptic or the monitoring and surveillance of private, intimate and emotional life; and predictive analytics or the preference for finding correlations among millions of available everyday data that intends, if not to explain the cause of phenomena, to look for new forms of coercion. The reasons why the operation of these devices makes contemporary society a surveillance society are also explored. In expounding the characteristics of each of these devices, the article aims to reveal the role of surveillance in regulating social life. Finally, it reflects on the loss of freedom that brings about the trust and security gained as a result of voluntary or sometimes thoughtless submission to new, subtle and apparently innocent modes of control such as joining social media, subscribing to electronic services, or using any of the most popular search engines.

\section{Keywords (Source: Unesco Thesaurus)}

Surveillance society; panoptic; synoptic; predictive analytics; control devices. 


\section{Do livro vermelho de Winston a Black Mirror. dispositivos de controle na sociedade da vigilância}

\section{Resumo}

Este artigo apresenta uma reflexão teórica sobre a vigilância como dispositivo garantidor da ordem social. Afirma que a nova estrutura de vigilância advinda da internet tende ao controle total da vida mediante a coação direta e violenta, ou o entretenimento e a diversão. Trata-se de três dispositivos de vigilância significativos: o panóptico como ponto de encontro entre a sociedade disciplinar que já não somos e a sociedade de vigilância que começamos a ser; o sinóptico ou o controle e a vigilância da vida privada, íntima e emocional; e a análise preditiva ou a preferência pela busca de correlações entre milhões de dados disponíveis sobre o cotidiano que pretende, se não explicar a causa dos fenômenos, buscar novas formas de coação, bem como das razões pelas quais o funcionamento desses dispositivos faz da sociedade contemporânea uma sociedade da vigilância. Ao expor as características próprias de cada um desses dispositivos, este artigo pretende mostrar o papel da vigilância na regulamentação da vida social. Por último, propõe reflexões da perda de liberdade que traz consigo o ganhar confiança e segurança produto da submissão voluntária ou, em alguns casos, sem reflexão a novos modos de controle sutis e em aparência inocentes, como o pertencimento a redes sociais, a assinatura eletrônica de diferentes serviços ou a mera consulta em algum dos buscadores mais populares.

\section{Palavras-chave (Fonte: tesauro da Unesco)}

Sociedade de vigilância; panóptico; sinóptico; análise preditiva; dispositivos de controle. 


\section{Introducción}

El edificio cerrado sobre sí mismo en cuyo centro había una torre donde los vigilantes podían ver, gracias a un juego de persianas, luces y sombras, todo lo que sucedía en las celdas de los presos o de los trabajadores fue reemplazado por la presencia de una pantalla de televisión que, además de transmitir los mensajes alentadores del Gran Hermano, podía también detectar cualquier anormalidad que pusiera en peligro el orden en Oceanía. Aquella pantalla chillona y fija ha sido reemplazada, a su vez, por ese dispositivo delgado y brillante como un espejo que todos llevamos en nuestros bolsillos y carteras, y que va, paso a paso, literalmente, registrando hasta los detalles más nimios de nuestra existencia sin que muchos de nosotros siquiera nos enteremos de ello.

Frente a la vigilancia, la telepantalla icónica de 1984 (Orwell, 1949/2018) presenta, por lo menos, dos líneas de fuga. En primer lugar, hay zonas ciegas a las que el Gran Hermano no puede dirigir su mirada. Pequeñas y recortadas, como en la habitación de Winston, o lejanas e imperfectas, como en el barrio de los "proles", esas zonas ciegas hacen posible, al menos durante unos pocos instantes de la cotidianidad, escapar de su mirada. En segundo lugar, la policía del pensamiento no puede actuar allí donde no hay evidencia de una transgresión, esto es, allí donde no hay palabras que atestigüen la resistencia a las normas. El pecado de Winston, si es que puede llamársele de este modo, consistió no en encontrar ese espacio ciego y libre de vigilancia en su apartamento, sino en comenzar a escribir un diario en su cuaderno empastado en rojo. El pecado de Winston consistió en hablar con Julia y con O’Brien a propósito de sus recuerdos y de las inconsistencias que encontraba de tanto en tanto en su trabajo en el Ministerio de la Verdad. No estaba obligado a hacerlo, no había ninguna norma que lo obligara a compartir con los demás sus más íntimos pensamientos, pero, como bellamente lo dice Foucault (2007) respecto de la confesión, una verdad clamaba por salir a la luz y proporcionarle, al fin, la liberación.

No sucede lo mismo con nuestros dispositivos electrónicos a los que deseamos tener cada vez más cerca. El teléfono o las tabletas inteligentes nos parecen ahora demasiado pesadas o engorrosas para cargarlas. Lenta- 
mente, las hemos ido reemplazado por relojes, también inteligentes, que atados a nuestras muñecas nos mantienen conectados con nuestros familiares y amigos, y nos dan mayor libertad de movimiento al no tener que mantener a la mano nuestros dispositivos de comunicación. ${ }^{2}$ Tenerlos cerca o portarlos en nuestras muñecas es todo lo que se requiere para acceder a los servicios de información y para hacer de nosotros, al mismo tiempo, un objeto y un sujeto constante y permanente de la vigilancia. Estos pequeños black mirrors, como adecuadamente los denominan los creadores de la exitosa serie de televisión, nos acompañan sin cesar y permiten el registro detallado y minucioso de nuestras actividades cotidianas a un nivel que, muchas veces, escapa a nuestra conciencia.

Este artículo pretende mostrar que la interacción de los tres dispositivos de vigilancia más significativos en la actualidad permite nombrar a la sociedad contemporánea como una sociedad de la vigilancia. Para ello, y siguiendo la indicación de Haggerty (2006) según la cual no es posible emprender un estudio sobre la vigilancia sin hacer referencia al panóptico (o bien para continuar por esa línea, o bien para distanciarse de ella), se retoman, en primer lugar, los planteamientos de Foucault (1989) y de Bauman (2007) sobre dicho dispositivo de control, para pasar luego al sinóptico y, por último, al campo de la analítica predictiva en la que se pueden encontrar los más recientes desarrollos en esta materia.

\section{Panóptico}

Es un tanto paradójico que una descripción física tan conocida haya tenido tan poca aplicación práctica y aun así sirva de referencia para caracterizar el modelo por antonomasia de la vigilancia: el edificio más importante es la torre central llena de persianas que se mueven para ocultar al vigilante que dirige su mirada a las celdas del edificio que la circunda, donde los internos (sean estos presos, estudiantes, enfermos o trabajadores, poco importa), merced a un juego óptico de luces y sombras, permanecen siempre

2 Si bien los relojes inteligentes han comenzado a tener más utilidad en el campo del entrenamiento físico y todavía no se extiende su uso de manera significativa (Hartmans, 2017), su uso se ha incrementado notablemente desde el lanzamiento del Apple Watch que, además de las funciones de salud, permite la consulta constante de las notificaciones de correo y redes sociales (Barrero, 2018). 
dispuestos para ser vistos, escudriñados, examinados y clasificados. Ese conjunto de edificios, nos dice Foucault, "debe ser comprendido como un modelo generalizable de funcionamiento; una manera de definir las relaciones de poder con la vida cotidiana de los hombres" (1989, p. 208).

El sueño de Bentham de una ciudad perfectamente gobernada se basaba en una sociedad con el mínimo de intervención por parte del Estado. El modelo del panóptico puede entenderse como un modelo de una sociedad perfectamente ordenada sin que sea necesaria la consideración de categorías metafísicas, como la educación moral, la integración cultural, la búsqueda del consenso o la coordinación y acuerdo respecto de los valores. Bauman (2007) lo describe así:

\begin{abstract}
Con una pizca de esfuerzo se puede leer el Panopticon como una parábola para la sociedad en general: una sociedad viable, una sociedad ordenada, una sociedad sin crimen y con la falta de cooperación fácilmente detectada y solucionada, una sociedad que busca activamente el mayor beneficio y la mayor felicidad para sus miembros, una sociedad completa con todas las funciones y papeles indispensables para su supervivencia y su éxito. En tal sociedad, demuestra el Panopticon, la libertad de algunos hace la dependencia de los otros tan necesaria como provechosa; mientras que la falta de libertad de una parte hace posible la libertad de la otra. (pp. 50-51)
\end{abstract}

Bauman presenta una novedosa forma de comprender el panóptico como una oposición entre libertad y falta de libertad. En la estructura piramidal con la que se le representa, los niveles superiores, en especial la cima de la pirámide, está compuesta por los empresarios quienes, guiados por su propio interés de ganancia y su temor a las pérdidas económicas, cuidarán de la salud y fortaleza de sus subalternos como condición necesaria para el adecuado empleo del tiempo y de la productividad en el trabajo. Sujetos a las leyes económicas de la oferta y la demanda, y compelidos a velar siempre por el incremento de su riqueza, no requieren un vigilante externo que oriente o guíe sus acciones. A lo sumo, aceptan algunas regulaciones estatales, siempre y cuando les otorguen las garantías suficientes para seguir en pos de su propio interés. Por su parte, los internos o subalternos prefieren garantizar su supervivencia en situaciones de menor incertidumbre y por 
eso aceptan, a cambio de alguna prestación económica, la normalización y el encauzamiento de sus conductas sociales y laborales. El sistema panóptico resulta, así, útil y, en cierta medida, provechoso para los vigilantes y para los vigilados, lo que refuerza a esta máquina como un instrumento adecuado para la instauración del autocontrol. En su descripción de la "fábrica panóptica”, Whitaker (1999) califica la vigilancia de reflexiva, pues mediante el control de la gestión no solo los trabajadores y empleados están bajo vigilancia, sino que este control permite, de manera automática o sincrónica, la evaluación de la gestión en sí misma. Esto hace de la vigilancia panóptica un dispositivo de control productivo y económico.

Conforme se va descendiendo por la estructura panóptica, se van perdiendo grados de libertad por parte de los vigilantes quienes son, a su vez, vigilados por otros de mayor rango que gozan de más autonomía. Sus acciones van perdiendo independencia y es menor su capacidad para influir o modificar la acción de los trabajadores o internos. En el nivel más bajo, ocupado en la estructura empresarial por el obrero raso, es necesario sustituir la propia voluntad por la voluntad de los supervisores y adaptar la propia conducta a los mandatos, a veces racionales, otras veces caprichosos, de los vigilantes. Así, el modelo panóptico proporciona una estructura de control total en todos sus niveles. Cabe anotar que solo en el nivel superior el empresario es el único actor que combina a la perfección "la independencia de y el dominio sobre [las cursivas son mías]” los internos (Bauman, 2007, p. 42).

Sin embargo, en el modelo propuesto por Bentham, el interno no es una "simple marioneta con miembros articulados por cuerdas externas solamente" (Bauman, 2007, p. 41). Son seres pensantes y calculadores, movidos también por su interés y deseo personal, pero que deciden no hacer uso de su libertad a cambio de una comprensión de la felicidad entendida como "paz y calma” fundada en la confianza en que sus superiores (padres, maestros, jefes, etc.) saben qué es lo que más les conviene. En cierta medida, los miembros de los estratos más bajos de la estructura se someten voluntariamente a una dominación que les asegura el mantenimiento de las condiciones de vida consideradas como adecuadas por los miembros de los estratos más altos. 
En este sentido, el panóptico como síntesis de la antigua sociedad disciplinaria se fundaba en una relación de dependencia entre vigilantes y vigilados, y requería, además, la presencia física de ambos en un espacio cerrado sobre sí mismo donde fuera posible la normalización y el encauzamiento de la conducta:

Este espacio, cerrado, recortado, vigilado, en todos sus puntos, en el que los individuos están insertos en un lugar fijo, en el que los menores movimientos se hallan controlados, en el que todos Ios acontecimientos están registrados, en el que un trabajo ininterrumpido de escritura une el centro y la periferia, en el que el poder se ejerce por entero, de acuerdo con una figura jerárquica continua, en el que cada individuo está constantemente localizado, examinado y distribuido entre los vivos, los enfermos y los muertos - todo esto constituye un modelo compacto del dispositivo disciplinario. (Foucault, 1989, p. 201)

Más allá del orden instaurado por el manejo del espacio y su distribución funcional, así como por la localización exhaustiva de los individuos y de las posibilidades de clasificarlos permanentemente según el grado de destreza o utilidad, el principal beneficio del panóptico radica en su capacidad para "inducir en el detenido un estado consciente y permanente de visibilidad que garantiza el funcionamiento automático del poder” (Foucault, 1989, p. 204). Saberse visto todo el tiempo, ser consciente del poder de una mirada que no puede verificarse más que en sus efectos, pues su acción es a menudo discontinua, induce a los internos a un grado de coacción ligera, pues no depende del uso de la fuerza o del ejercicio de la violencia directa, a la que es difícil resistir. Además, poco importan el rango o el poder social del vigilante, pues para el adecuado funcionamiento de este aparato de vigilancia lo realmente importante y necesario es que el interno tenga la certeza de saberse mirado, escudriñado, examinado y, de este modo, se vea impelido a asumir las normas y reglas como propias, lo cual mina aún más sus posibilidades de resistencia. El panóptico deriva, entonces, sus mayores resultados en tanto el ejercicio del poder se mantenga, al mismo tiempo, visible e inverificable (Foucault, 1989).

Tres son los principios que permiten dilucidar si un tipo de vigilancia pertenece a la categoría del panóptico. En primer lugar, la vigilancia 
debe ser anunciada, declarada formalmente por los vigilantes. La conciencia de la mirada sobre sí es un elemento fundamental en cuanto genera en los vigilados la aceptación de los comportamientos prescritos y el asentimiento de ser vigilados permanentemente. En segunda instancia, la vigilancia panóptica se caracteriza por la disociación de la mirada. No existe una reciprocidad entre la mirada del vigilante y la del vigilado; ellos no pueden mirarse o escudriñarse mutuamente, solo el primero tiene ese privilegio. Al segundo solo le queda la permanente sensación de ser visto, seguro de que su comportamiento y su conducta están siempre sometidos a un riguroso escrutinio. Por último, y como ya se señaló antes, el panóptico requiere el aislamiento, la individualización de los vigilados, a fin de lograr que la mirada del vigilante sea más eficaz y pueda ocuparse en detectar las desviaciones o los comportamientos clasificados como inadecuados y operar las correcciones necesarias para mantener el funcionamiento del sistema al que se aplique. Además, facilita el establecimiento del orden, la clasificación por categorías y la medición de los resultados del desempeño. Dadas las dificultades logísticas para lograr separar a los individuos que trabajan o conviven juntos, el panóptico se sirve de todo un arsenal de reportes documentales (exámenes, historias clínicas o laborales, hojas de ruta, formatos de datos, etc.) que facilitan la labor de separación e individualización.

Según Foucault (1989), el panóptico presenta una doble utilidad: por un lado, sirve como instrumento de clasificación de los internos, cualquiera que sea el criterio utilizado para ello (productividad, eficiencia, obediencia o sujeción a las normas, grado de disciplinamiento, etc.) y, por el otro, sirve de laboratorio social, pues el confinamiento y la clasificación de los internos permite experimentar con diversas técnicas encaminadas al mejoramiento de las instituciones que se sirven de él. En ambos casos, es preciso contar, además de la observación de los internos, con un sistema de información que permita la clasificación y el registro minucioso de los resultados experimentales sobre la conducta. El panóptico proporciona, además de sujeción y obediencia, la posibilidad de creación de un saber sobre los internos y, con él, la posibilidad de profundizar en distintos aspectos de la conducta humana a fin de lograr apresarla para la eficiencia, la productividad y la rentabilidad: 


\begin{abstract}
El Panóptico es un lugar privilegiado para hacer posible la experimentación sobre los hombres, y para analizar con toda certidumbre las transformaciones que se pueden obtener de ellos. [...] El Panóptico funciona como un laboratorio de poder. Gracias a sus mecanismos de observación, gana en eficacia y en capacidad de penetración en el comportamiento de los hombres; un aumento de saber viene a establecerse sobre todas las avanzadas del poder, y descubre objetos que conocer sobre todas las superficies en las que este viene a ejercerse.
\end{abstract}

(Foucault, 1989, p. 208)

Tal vez la gran limitación de esta herramienta de control radica en la necesidad del cerramiento del espacio físico. Si bien es posible controlarlo todo en los centros de encierro, la vida al aire libre, los modos de utilización del espacio público, el tiempo dedicado al ocio y, más importante aún, la vida íntima de los internos escapa a esta forma particular de la mirada. Según Haggerty (2006), las discusiones respecto de la superación o no del modelo panóptico están lejos de terminar. A pesar de ello, es cierto que las nuevas formas de la vigilancia instauradas a partir de la revolución de la información han hecho posible prescindir del encierro y penetrar más profundamente en la vida social e íntima de los vigilados. El control ultrarrápido al aire libre del que hablaba Deleuze (1995) requiere nuevas máquinas de vigilancia que, si bien no reemplazan completamente el panóptico, sí lo complementan. El sinóptico, tema que trataremos a continuación, es una máquina de vigilancia más amigable para con los vigilados y, justo por ello, menos susceptible a la resistencia.

\title{
Sinóptico
}

$\mathrm{Al}$ abandonar las paredes frías y cerradas, la vigilancia se ha difuminado (Bauman y Lyon, 2013, p. 10), se ha vuelto líquida o, tal vez, gaseosa. Las tecnologías de la información y de la comunicación (TIC) permitieron que los dispositivos de vigilancia se adueñaran de los espacios abiertos y públicos, y así inauguraron el establecimiento de la llamada sociedad de control. Inicialmente, gracias a las posibilidades creadas por los circuitos cerrados de televisión y, luego, mediante las cámaras instaladas en los aparatos de comunicación móviles. En este contexto, no solo cambiaron los métodos de vigilancia, sino también su propósito, de modo que este es uno de los cambios cualitativos más relevantes de este proceso de transición. Si el panóptico 
buscaba mantener una cierta conformidad con una norma que prescribía el comportamiento correcto y uniformaba a los internos para facilitar la detección y posterior corrección de las desviaciones, los nuevos modos de la vigilancia abandonan la pretensión de normalización y se centran, o bien en la exclusión de los desviados, o bien en la incitación, motivación o seducción hacia un ideal de vida buena fundada en el consumo. Este segundo objetivo implica que la vigilancia contemporánea se use para algo más que la mera conformidad con las normas y pueda incluso favorecer la libertad de consumo, incrementar la salud individual, la productividad empresarial, el disfrute sexual o servir como simple y llano entretenimiento. El cumplimiento de estos fines hace necesario incrementar la capacidad de vigilancia (Lyon, 1995) para poder predecir y diseñar los comportamientos futuros. Como bien lo dice Bigo (2008, p. 109), es necesario rastrear todo lo que se mueva (productos, información, capital, personas).

La posibilidad de operación en los espacios abiertos permitió transformar la captura de la información. Otrora regulada por un estricto sistema jerárquico que cuidaba la distribución de la información, en la actualidad la estructura de la vigilancia tiene un carácter rizomático, pues esta se realiza mediante una estructura completamente descentralizada a través de miles o quizá millones de aplicaciones e interacciones en la red mundial de información. La fluidez característica se extiende también al procesamiento de la información mediante un complejo e intrincado flujo de datos que circula libremente entre distintas organizaciones tanto públicas como privadas y que, además, trascienden las fronteras nacionales. Esta estructura rizomática hace parecer la vigilancia como algo "natural" y obvio, y pocos reparan en ella. Los datos se consiguen fácilmente gracias a la cooperación de los usuarios, pues, como se indicó antes, esta actividad se ha vuelto entretenida y divertida. Gracias a esto, "el miedo a ser observado ha sido vencido por la alegría de ser noticia” (Bauman y Lyon, 2013, p. 32).

Liberar la vigilancia de los espacios cerrados trajo consigo, también, la cesación de la relación de dependencia que caracterizaba la relación entre los vigilantes y los vigilados. Bauman y Lyon (2013) llaman la atención respecto de que estas formas de vigilancia permiten hacer cosas a la dis- 
tancia, por lo que separan a las personas de cualquier consideración moral que se derive de sus acciones y de las consecuencias que ellas pueden traer para aquellos en quienes recaen. A este fenómeno se refieren con el término "adiaforización" (p. 16).

En este contexto, la captura de los datos tiene una forma parecida a la confesión, entendida no como la revelación de un secreto que atormenta y quita la paz, sino como una "afirmación de la autenticidad del yo" (Bauman y Lyon, 2013, p. 36). La confesión moderna permite que la privacidad abandone el ámbito de lo íntimo y colonice el terreno de lo público. Este tránsito tiene como consecuencia un abandono del secreto que es su característica más esencial, pues es la frontera que define el dominio de lo propio "dentro del cual cada uno tiene el poder total e indivisible para decidir 'quién y qué soy' y desde el cual cada uno puede intentar una y otra vez que sus decisiones sean reconocidas y respetadas" (p. 36). La privacidad, antes entendida como un espacio de libertad, es percibida hoy como un lugar de confinamiento o de condena. Esta pasión por la confesión que alimenta las bases de datos que soportan la vigilancia contemporánea le da pie a Bauman para declarar que estamos en una sociedad confesional:

[Una] sociedad en la que se elimina la frontera que antes separaba lo privado de lo público, que convierte la exposición pública de lo privado en una virtud pública y en una obligación, y también que excluye de la comunicación pública a cualquiera que se resista a ser reducido a sus confidencias privadas, junto con todos aquellos que se niegan a hacer confidencias. (Bauman y Lyon, 2013, p. 38)

La cercanía que promueve la comunicación en línea es superficial, fría, rápida, mecánica, no requiere ningún esfuerzo y está prácticamente exenta de riesgos. Este tipo de cercanía, más que una comunidad, produce una red de contactos en la que cada miembro, si bien gana estados de libertad, pierde seguridad en tanto las consecuencias de sus acciones dependen, exclusivamente, de sus decisiones sin que medie una suerte de "red de apoyo" capaz de soportarlo en los momentos difíciles. Quienes se relacionan a través de las redes sociales o de información tienen poca conciencia de la existencia de normas y de su cumplimiento. Prácticamente solo cumplen, sin percibirlas, aquellas que están asociadas al diseño de las pantallas y de 
las facilidades de interacción. Pero estas no se ven como normas de comportamiento o de conducta que coartan la libertad, sino como posibilidades de interacción y comunicación con otros a las que no es necesario resistirse. La comunidad proporciona seguridad y confianza, pero exige obligaciones e impone restricciones. Esto no sucede con las redes sociales, pues en ellas el individuo queda exento de las obligaciones y restricciones que impone la vida comunitaria.

Utilizadas principalmente como medio para la diversión, las redes sociales promueven vínculos débiles, relaciones a corto plazo, compromisos siempre provisionales y resaltan los derechos de los usuarios más que las obligaciones sociales. Las redes sociales se fundan en el individualismo y en la satisfacción personal, sus algoritmos se construyen para presentar la información que más se acomode a los gustos y a las preferencias de los usuarios y crean un "mundo propio" que resulta cómodo para la mayoría de ellos. Aunque su nombre hace pensar en la creación de comunidades y grupos, y se pudiera pensar que tienen un interés comunitarista, lo cierto es que pretenden satisfacer demandas y deseos meramente individuales. En este sentido, la fragilidad de los vínculos sociales trae consigo una escasa disposición para ayudar y ser ayudados por otros, lo que contribuye al estado de fragmentación social en la que el individuo queda librado a su propia suerte siendo el único responsable por su bienestar.

En el sinóptico, se transforma el régimen de visibilidad del panóptico. Dicho de otro modo, pasamos de una fórmula según la cual "uno los ve a todos" a una en la que "todos ven a uno", sea este un programa de televisión, un youtuber famoso o la simple interacción en redes sociales. Respecto de estas últimas no se puede olvidar que son un espacio que desde su diseño tiene incluida la vigilancia como aspecto fundamental de su funcionamiento.

Debido a que este dispositivo se refiere más a una serie de prácticas que no requieren su inscripción en un espacio físico determinado, se hace más fácil satisfacer la hoy imperante necesidad de ser visto. En este sentido, el sinóptico conjura el miedo de sentirse siempre observado con la alegría y el placer de sentirse en compañía de sus vigilantes u observadores, 
pues a lo que se le teme no es a la vigilancia o posible corrección del comportamiento, sino a la exclusión social que, en últimas, representa la mayor pérdida de seguridad. Es en este sentido que ser vigilado (visto) equivale a ser reconocido socialmente. Otra de las características importantes de este dispositivo es que sus efectos se obtienen tanto del imperativo social por la exhibición de los vigilados como del gusto y la diversión voyerista de los vigilantes, pues en el entorno digital una misma persona cumple, simultáneamente, los dos roles. Además, "lo que se extiende ante los ojos del guardián adquiere las características del espectáculo, pues cada miembro de la sociedad digital se comporta como espectador ante la vida desplegada por los demás” (Manjarrés, 2017, p. 97).

El aparato de visión del sinóptico se enfoca en la vida emocional, en la administración de las sensaciones y de los deseos. Este tipo de herramienta, denominada por Han como panóptico digital, busca "intervenir la psique y condicionarla a un nivel pre-reflexivo” (2014, párr. 256), pues para incrementar la productividad, necesaria ahora para el consumo más que para la producción o el trabajo, es preciso entonces optimizar los procesos psíquicos y mentales.

Si bien el uso del espectáculo como medio de control puede rastrearse hasta el mundo griego antiguo, en la actualidad la vida, como acertadamente lo expresa Debord, "se anuncia como una inmensa acumulación de espectáculos [las cursivas son mías]” (2002, p. 37) que es preciso presenciar desde la oscuridad y, quizá, desde el ocultamiento en las gradas de un inmenso centro comercial que hace las veces de teatro. El consumo, en sus tres formas principales, "hedonista, de experiencias y ontológico" (Manjarrés, 2017, p. 61) se convierte en el modo de organización del sistema capitalista que realiza la vigilancia principalmente a través del marketing.

El régimen de visibilidad propuesto por el sinóptico se fundamenta en la consigna "muchos ven a uno o a unos pocos". En este sentido, se evidencia un cambio insólito en la forma de vigilancia: ser vigilado no consiste ahora en ser visto sino en ver. Esta transformación tiene dos objetivos: primero, mostrar o exhibir un modelo de comportamiento ideal que no es 
impuesto por una coacción directa o acaso violenta, sino mediante la cuidadosa escenificación de las recompensas y, acaso, de los castigos que conllevará el seguimiento —o la evitación — de los parámetros de normalidad, pues "el poder que entretiene [las cursivas son mías] es más poderoso que el poder que trabaja con la coerción” (Han, 2018, párr. 423). Segundo, el uso de imágenes seductoras que transforman el abanico de deseos de aquellos que observan y los mueve a aceptar, de manera casi imperceptible, el diseño que unos pocos hacen de sus vidas. En este sentido, "el sujeto del espectáculo recibe del sinóptico, no solo lecciones prácticas sobre cómo evitar castigos y obtener recompensas, sino también qué es deseable ser" (Manjarrés, 2017, p. 103).

Aunque el surgimiento del sinóptico no puede atribuirse a los inicios o al desarrollo de la sociedad de la información, sí que es cierto que este dispositivo ha amplificado su productividad a partir de la aparición de la red mundial de información. Una de las consecuencias de la masificación de internet y de lo que se conoció como web 2.0 es la capacidad que los miles de millones de usuarios tienen de interactuar con las empresas, las instituciones, los organizaciones y los medios de comunicación de todo el mundo. Esta interacción abrió la posibilidad para la aplicación aditiva de los dos modos de vigilancia descritos hasta ahora: el panóptico y el sinóptico, y así permitió un ensanchamiento de los campos de visión y los acercó a lo que Los (2006) señala como un nuevo potencial totalitario.

Si bien el panóptico es un modo de vigilancia que puede calificarse de fuerte (Lyon, 2006), lo cierto es que este dispositivo solo se ocupa de los comportamientos que exhiben los internos en tanto están sometidos a la vigilancia. En otras palabras, este aparato de vigilancia incluye una línea de fuga (Bogard, 2006) en la que los individuos, lejos del alcance de la vigilancia, pueden ser y desear lo que quieran ser sin que los vigilantes puedan interferir. Por más pequeño que sea ese espacio, como el rincón del apartamento de Winston (Orwell, 1949/2018), o por más fuertes que sean las reacciones contra la vigilancia, el panóptico, por las limitaciones espaciales, el procesamiento jerárquico de la información y la restricción de los campos de visión, no puede abarcarlo todo. En palabras de Han, si bien el panóptico pretende una transformación moral de los internos, lo cierto es que 
la psique no está en el punto de mira del poder disciplinario. La técnica ortopédica del poder disciplinario es muy burda para penetrar en las capas profundas de la psique con sus anhelos ocultos, sus necesidades y su deseo, y acabar apoderándose de ellas. El Big Brother de Bentham también observa a sus reclusos desde el exterior. Su panóptico está ligado al medio óptico. No tiene ningún acceso al pensamiento 0 a las necesidades internas. (2014, párr. 380)

El vacío dejado por el panóptico pretende ser cubierto por el sinóptico y su característica proliferación de imágenes que proyectan, a cada instante y en cualquier espacio, los ideales de vida propuestos por el capitalismo de consumo. Como lo afirma Manjarrés,

el conjunto de los mensajes distribuidos por el sinóptico constituye un paradigma del mundo, y para que opere como instrumento de control, ese paradigma debe responder a una intención, debe ser producido o distribuido para transmitir un mensaje. Aunque la producción sea, en ocasiones, fruto de la casualidad, la intención y la estrategia en la distribución del mensaje transforman una observación casual en sinóptico. (2017, p. 108).

El consumo de imágenes se convierte, entonces, en el medio que permite una transformación de la conciencia, sobre todo si este está marcado por la diversión y el entretenimiento. El consumo de imágenes del mundo propiciado por la publicidad y el entretenimiento ligero refuerza la pasividad característica del espectador y dificulta las posibilidades de resistencia. Además, es prácticamente imposible escapar de ellas, pues están en todas partes, no se puede simplemente no verlas, ocupan todos nuestros espacios. Su aparición sutil y poco violenta dificulta, aún más, la resistencia.

Ahora bien, hay otro elemento que caracteriza al sinóptico: la variedad de presentaciones que adopta el paradigma del mundo propuesto por el capitalismo de la información es tan variopinto que se hace difícil encontrarle una unidad o una intención unificadora. La individualización lograda por los sistemas de procesamiento de información y presentada como una estrategia efectiva de personalización (Lipovetsky, 1998) dificulta la percepción de este modo de vigilancia. El bombardeo de las imágenes al que somos sometidos diariamente respecto de ideales o imágenes de lo que constituye - y al mismo tiempo amenaza - al bienestar hace que los 
ciudadanos dejen de confiar en la protección del Estado y personalicen sus temores respecto de la supervivencia y vean en el consumo un modo de escapar a ellos. La analítica predictiva permite la individualización de dichas imágenes y facilita la operación del sinóptico como herramienta de control.

Para terminar la exposición sobre el sinóptico, es pertinente hacer mención de las redes sociales como el lugar por antonomasia que facilita y promueve su funcionamiento. Estas plataformas digitales les han permitido a sus usuarios expresarse y comunicarse al margen, al menos en apariencia, de los grandes emporios de la comunicación tradicional de masas. De ahí que, al inicio de esta revolución electrónica, se hablara con tanta frecuencia de la posibilidad de darles voz a aquellos a quienes por generaciones habían sido silenciados.

Sin embargo, la ya célebre regla del 90-9-1, propuesta por Nielsen (2006), y conocida como "desigualdad en la participación", estima que el $90 \%$ de los usuarios de las redes sociales pueden ser clasificados como simples "mirones", personas que solo ven las publicaciones de otros, pero que no publican nada sobre sí mismos ni interactúan con las publicaciones de los demás; el $9 \%$ de los internautas interactúan con las publicaciones de los demás y solo en contadas ocasiones publican algo propio y solo el $1 \%$ contribuyen con contenido. Según esta regla, el panóptico digital solo opera sobre dicho porcentaje de la población usuaria de las redes sociales mientras que el sinóptico tiene efectos, directos o indirectos, sobre el $99 \%$ restante (Manjarrés, 2017). No es casual que redes sociales como Instagram o Twitter hayan eliminado la categoría de "amigos" iniciada por Facebook, que aludía a una relación de aparente simetría, por la de "seguidores" e "influyentes" que remite a una cierta relación de subordinación en la que los primeros reaccionan, $\mathrm{y}$ muchas veces acatan, las propuestas o mandatos normalizadores de los segundos.

Un estudio publicado por Chou \& Edge (2012) llama la atención sobre el efecto que tiene la observación de lo que los amigos comparten en Facebook. Según estos autores, al recordar las fotografías y publicaciones de sus contactos, los observadores tienden a sobrevalorar la vida de los de- 
más y a menospreciar la propia. Esto, fundamentalmente, porque, para mejorar la imagen generada sobre los demás, la gente tiende a publicar solo los aspectos positivos y felices de sus vidas, y deja de lado cualquier evento negativo. Además, el estudio del grupo liderado por Coviello et al. (2014) ha constatado que las expresiones individuales de las emociones dependen en gran medida de lo que los contactos en las redes sociales están publicando. Según estos autores, las emociones de los usuarios tienden a sincronizarse con las de su grupo más cercano, lo cual propicia un "incremento en la volatilidad en todo, desde sistemas políticos hasta mercados financieros” (p.5).

Finalmente, el sinóptico conforma dos elementos particulares. La publicación que un usuario de las redes sociales realiza con la intención de mostrar o exhibir su propia vida y el conjunto de comentarios que el $9 \%$, según la regla de Nielsen, construyen sobre el material publicado. No obstante, el $90 \%$ restante también se ve afectado por estas publicaciones y, a pesar de no expresar ninguna reacción en línea, es influenciado por ellas, somete su vida a un permanente examen cuyos parámetros fluctúan según fluyan las publicaciones o modas prescritas por aquellos que cumplen el papel de influenciar y orientar las vidas de los otros. Poco interesa si lo publicado es real o imaginario, verdadero o falso. ${ }^{3}$ Lo cierto es que la información que un usuario determinado elige (no siempre de manera consciente) publicar en sus redes sociales, ese pequeño mundo personal que ahora tenemos oportunidad de crear, está influenciado por lo que él considera que será aprobado por su red de referencia o por las posibilidades de crear tendencias que modifiquen, al menos parcialmente, el comportamiento de los demás (Bichieri, 2019). Este juego de información, que hace transparente a un sujeto que aparece en redes, permite forjar al

3 Según un estudio publicado en noviembre de 2016 (Drouin, Miller, Wehle \& Hernandez, 2016), se puede evidenciar que, cuanto más oscura o profunda sea la red social con la que se interactúe, más posibilidades habrá para la publicación de información falsa sobre los usuarios. Esto en sí mismo no sorprende, pues es sabido que la internet profunda, también conocida como Darknet, es usada para asuntos que no solo rayan con la legalidad o con lo socialmente aceptado, sino que son utilizadas por los emporios del tráfico de drogas, mujeres, personas, armas y pornografía infantil, por solo mencionar algunos. Lo que parece ser más interesante en el artículo es que los investigadores pudieron constatar no solo que la gente miente respecto de su información porque tenga algo que ocultar de los demás, sino porque considera que los demás también lo hacen. Así que, podríamos inferir, proporcionar información incompleta, falsa o imaginaria sobre nuestro comportamiento no es solo algo que creamos que es correcto, sino que lo creemos porque creemos que los demás lo hacen. 
sujeto de rendimiento extensamente descrito por Han y todo esto lo hace en nombre de la libertad de elección:

Hoy creemos que no somos un sujeto sometido, sino un proyecto libre que constantemente se replantea y se reinventa. Este tránsito del sujeto al proyecto va acompañado de la sensación de libertad. Pues bien, el propio proyecto se muestra como una figura de coacción, incluso como una forma eficiente de subjetivación y de sometimiento. El yo como proyecto, que cree haberse liberado de las coacciones externas y de las coerciones ajenas, se somete a coacciones internas y a coerciones propias en forma de una coacción al rendimiento y la optimización. (2014, párr. 105)

\section{Analítica predictiva}

La analítica predictiva se ha convertido en una herramienta muy eficaz para el ejercicio de la vigilancia contemporánea, pues no es un secreto que los datos son, hoy día, el activo con mayor potencial para la generación de riqueza. Se refiere al análisis de datos que solo puede hacerse a escala mayor "para extraer nuevas percepciones o crear nuevas formas de valor, de tal forma que transforman los mercados, las organizaciones, las relaciones entre los ciudadanos y los gobiernos, etcétera” (Mayer-Schönberger \& Cukier, 2013, párr. 145). Allí donde la estadística descriptiva pretendía encontrar causas de los fenómenos, la analítica predictiva busca correlaciones entre estos para buscar descripciones o explicaciones respecto de su ocurrencia. Mientras las otras formas de control aquí expuestas operan fundamentalmente sobre hechos que ya han pasado y que se salen de los parámetros de normalidad (panóptico) o actividades y eventos que ocurren en el presente (sinóptico), la analítica predictiva busca apoderarse del futuro para diseñarlo y reducir, lo más posible, la incertidumbre e indeterminabilidad características del futuro. ${ }^{4}$

Gracias a los desarrollos realizados durante el siglo XX en materia de procesamiento de la información, fue más fácil segmentar los mercados y

4 Si bien la prevención o el deseo de predecir y controlar el futuro está en la entraña de las ciencias sociales desde su inicio, Whitaker (1999) señala que esta ansia por predecir y normalizar el comportamiento futuro no solo es una herencia del viejo aparato panóptico, sino que es una de las causas por las que ha ido aumentando (el autor no da pruebas estadísticas) la aversión al riesgo. 
estratificar las poblaciones para optimizar la oferta y distribución de productos y servicios proveídos, o bien por el Estado, o bien por las organizaciones y empresas privadas. Sin embargo, gracias a la masificación de internet y al uso extensivo de redes sociales y de servicios de búsqueda de información, el análisis de datos masivos pudo desarrollar "tecnologías de procesamiento de datos que prescinden de las jerarquías rígidas y de la homogeneidad de antaño" (Mayer-Schönberger \& Cukier, 2013, párr. 137) y centrarse en la búsqueda de correlaciones en reemplazo del análisis de la causalidad de los fenómenos. El análisis masivo de datos se refiere, entonces, a una herramienta matemática que aplicada a una enorme cantidad de información permite hacer predicciones o inferir probabilidades para modificar los modos de comprender los fenómenos que componen nuestra vida y facilitar el orden social (Arango, 2018). Su objeto no es ya ni el cuerpo físico ni el alma individual, sino la data-imagen, entendida como el conjunto de datos y pistas que los usuarios de la red mundial de información van dejando tras cada interacción. Así, los algoritmos que configuran los motores de búsqueda de las redes sociales y demás servicios de información aprovechan los datos personales, las interacciones en las redes y hasta las búsquedas inocentes en internet para configurarle al usuario un mundo posible donde prime la sencillez, se anule la confrontación y se aumente la resistencia ante lo distinto o diferente. Este tipo de control es suave y muy potente, pues no requiere una intervención directa sobre el cuerpo físico y porque se aplica antes de que los usuarios se percaten de ello.

El incremento exponencial de la información personal disponible en red, así como el incremento en la capacidad de almacenamiento de los datos - y los nuevos modos de procesarlos que eliminan las barreras que antaño poseían las bases de datos estructuradas - hacen posible que un puñado de empresas en todo el mundo puedan procesar una ingente cantidad de datos y convertirlos en predicciones útiles del comportamiento de los miles de millones de usuarios de dicha información.

La vigilancia de datos se erige entonces como la herramienta que posibilita el monitoreo sistemático de las acciones o comunicaciones de las personas a través de la tecnología de la información (Genosko \& Thompson, 
2006). Se trata, entonces, de recopilar cualquier tipo de información, no importa su valía inmediata, para poder establecer relaciones y hallar correlaciones que permitan predecir el comportamiento individual y comunitario. Por ejemplo, acumular los datos de localización o movilidad a través de Waze y otras aplicaciones usadas para tal fin les facilita a las autoridades gubernamentales predecir posibles trancones o la ocurrencia de accidentes sin necesidad de acudir al monitoreo directo de los automóviles. De igual manera, implantar chips, sensores y pequeñísimos módulos de comunicación a los electrodomésticos y otros objetos cotidianos facilita una interacción permanente con las grandes cadenas de supermercados sin que sea necesaria la participación del usuario.

En pocas palabras, el proyecto de la analítica predictiva consiste en una cuantificación del ser que excluye cualquier proceso narrativo. Esta forma de control se fundamenta en la mera adición de datos y hechos sin que sea importante o necesaria la unidad de estos datos en una narración o historia personal cargada de sentido para cada individuo. La acumulación de datos biográficos o comunitarios no permite responder las preguntas por la identidad o el sentido. Los números, como afirma Han (2014), son solo aditivos; no son una práctica del cuidado de sí, sino una mera técnica de control. Esta técnica pretende

\begin{abstract}
reemplazar la capacidad humana para juzgar aquello que conviene 0 es provechoso por mandatos emanados de sistemas computacionales que de manera automática van creando nuevos y, en apariencia, mejores modelos de normalidad. Los ideales respecto de lo bueno, lo bello o lo justo [...] han sido reemplazados por la tiranía de la mayoría, por correlaciones en apariencia fútiles que parecen abandonar cualquier ideal ético o moral en beneficio de la moda, la media 0 la desviación estándar como medidas utilizadas para desentrañar el comportamiento humano. (Arango, 2018, p. 105)
\end{abstract}

La vigilancia de datos, según advierte Bogard (2006), se ha democratizado, es descentralizada, está menos sujeta a limitaciones espaciales y temporales, y gracias a su estructura rizomática, es menos organizada en sus procesos, pero más efectiva en sus resultados. Al centrarse en la obtención y en el análisis detallado de la información personal, la vigilancia ordena y asigna categorías y las valora, y establece riesgos que afectan las oportuni- 
dades de vida de las personas, pues la codificación de las actividades diarias (llamadas, visitas, desplazamientos, transacciones, interacciones en redes sociales, búsquedas de información, etc.) abren o cierran las posibilidades de participación en una multitud de eventos, experiencias y procesos. La clasificación social emanada de los procesos de vigilancia electrónica se diseña para el manejo de poblaciones e individuos, $y$ orienta directa o indirectamente sus oportunidades o decisiones (Lyon, 2003). Aunque la captura de los datos obedece a esa estructura rizomática, su procesamiento y las consecuencias que de ello se derivan tienen una estructura oligopólica dominada por un puñado de empresas de tecnología (BigTech) cuyo objetivo es predecir o diseñar tendencias y comportamientos.

Desde el punto de vista del mercado, la clasificación social producida por la vigilancia se utiliza para incentivar el consumo, diseñar productos personalizados a la medida e incrementar la velocidad y el automatismo de las compras. Además, se utiliza como una herramienta para enfrentar el entorno altamente competitivo del mercado global. Por otro lado, la vigilancia policial o gubernamental permite el perfilado de aquellos que han de ser considerados, sin que exista prueba de ello, como potencialmente peligrosos y, de este modo, establecer estrategias para el control del crimen y el mantenimiento del orden social. Normalmente este tipo de perfilado se orienta a aquellos en condición de necesidad o que operan por fuera o en los límites del mercado, tales como los desempleados, los enfermos, los solteros y los pobres.

En ambos casos, los sistemas de vigilancia obtienen datos personales para clasificar a la gente y a las poblaciones de acuerdo con una variedad de criterios para determinar quiénes pueden ser objeto de tratamiento especial, sospecha, elegibilidad, inclusión, acceso, etc. La técnica del perfilado permite que automáticamente, gracias a los algoritmos que conforman los sistemas electrónicos de la vigilancia, se efectúen decisiones binarias entre la exclusión o la inclusión, la separación o la integración, la presencia o la ausencia y la indiferencia o la consideración a ciertos individuos o grupos poblacionales. Esto afecta la vida personal, porque altera el estilo de vida, las decisiones y las elecciones de las personas quienes 
se ven compelidas a adaptar su identidad a los parámetros sociales para no ser objeto de algún tipo de exclusión social, política, religiosa o económica (Lyon, 2003).

Para que esta herramienta rinda sus frutos, se requiere la cooperación de millones de personas que en todo el mundo realizan sus actividades acompañadas de una cantidad asombrosa de aplicaciones que registran todo cuanto sucede en la vida cotidiana: los pasos, el pulso cardiaco, las rutas utilizadas para llegar al trabajo, las personas con quienes conversamos y la duración de esas conversaciones, los datos médicos, los libros que leemos, la velocidad de la lectura, etc. Nada se torna inútil, pues en la búsqueda de correlaciones que puedan indicar algún patrón de comportamiento todo está permitido. Así, el dato más inocente parece tener un enorme potencial predictivo si se le puede correlacionar con otros datos.

Entre los riesgos que entraña esta nueva técnica de procesamiento de datos, se encuentra, en primer lugar, la pérdida de la privacidad. Los acuerdos de protección de datos no siempre funcionan porque no se puede prever el uso que las distintas empresas les darán a los datos en el futuro, pues estos son un tipo de bien que no pierde el valor con su uso y pueden ser utilizados una y otra vez con propósitos diferentes. Además, cada vez son más intrincados los sistemas que permitirían la protección de los datos personales, pues el acceso a aplicaciones y páginas de información requiere la aquiescencia de los usuarios para el tratamiento de sus datos. Esta vigilancia algorítmica de la vida tiende a volver obsoletos e inoperantes los medios legales establecidos para proteger la intimidad.

La vigilancia cotidiana dejó de estar confinada a una región geográficamente determinada. Así como la vida cotidiana se ha tornado más fluida, la vigilancia también lo ha hecho. Ambas cosas gracias a las redes de información y de comunicación. Para aquellos cuyos riesgos provienen, fundamentalmente, de una situación precaria, a nivel personal o familiar, la vigilancia usa medidas intrusivas, impertinentes e invasivas para verificar la salud, el empleo y otras variables asociadas a los riesgos individuales. 
En segunda instancia, y como ya se ha insinuado antes, la analítica predictiva y sus distintas técnicas, entre ellas el perfilado electrónico, incrementan los niveles de peligrosidad y la cuantificación de los riesgos: es decir, para la vigilancia algorítmica, todos somos objetivos de supervisión, objetos de sospecha potencial no solo de cometer un delito, sino de ir contra las reglas sociales imperantes. En este sentido, "los algoritmos predecirán la probabilidad de que uno sufra un ataque al corazón ( $y$ tenga que pagar por un seguro médico), deje de pagar la hipoteca ( $y$ se le niegue un crédito) o cometa un delito ( $y$ tal vez sea detenido antes de los hechos)" (Mayer-Schönberger \& Cukier, 2013, p. 344). Además, el seguimiento a los datos personales realizado, entre otras muchas agencias, por las compañías de seguros, crean patrones de normalización del comportamiento, presentes y futuros, que escapan a los escenarios sociales y políticos donde estas normas son discutidas y acordadas por un grupo amplio de la comunidad. La normalización del comportamiento social se va atrincherando detrás de las líneas de código que programadores de todo el mundo y al servicio de muchas empresas e instituciones que operan fuera de la arena política van considerando como adecuadas a sus fines comerciales o industriales sin que los ciudadanos o los políticos puedan hacer algo para legitimarlas.

Elmer \& Opel (2006) señalan que como consecuencia de la vigilancia se establece una sociedad de supervivencia caracterizada por el hiperindividualismo y la ausencia de pensamiento crítico en cuanto los ciudadanos, convertidos ahora en consumidores, deben seguir haciendo compras y circulando en las arenas del mercado para evitar la vigilancia policial y la categorización como posibles individuos peligrosos.

Para cerrar este apartado, resulta útil la distinción planteada por Norris (2003) entre conocer a la gente y conocer sobre la gente. Mientras la primera requiere la interacción cara a cara y supone la humanización del otro, la segunda se funda en el conocimiento de segunda mano a través de los chismes, los rumores, la información clasificada y el establecimiento de estereotipos, y no requiere el reconocimiento de la diferencia o individualidad del otro. Mientras conocer $a$ la gente es la base de un orden público 
local y cercano, fruto de la deliberación democrática, conocer sobre la gente permite el control policial y la generalización de modelos de conducta globalmente aceptados como normales. La analítica predictiva se funda en un conocimiento profundo sobre la gente que, paradójicamente, mientras incrementa el distanciamiento físico entre las personas, posibilita la creación de pequeños grupos dispuestos a la solidaridad y el compromiso con aquellos a quienes considere sus semejantes. Las técnicas del perfilado y de la clasificación social utilizadas por la analítica predictiva no requieren la interacción entre humanos, basta con correlacionar enormes cantidades de datos para poder predecir o diseñar los parámetros de normalidad que regirán el comportamiento individual y social.

\section{Conclusiones}

El panóptico, el sinóptico y la analítica predictiva son tres dispositivos de vigilancia que hacen parte de lo que Bogard (2006) designa como "ensamblajes de vigilancia", esto es, un conjunto de componentes materiales e inmateriales, un complejo despliegue de cuerpos y máquinas, así como un orden de eventos, discursos, conceptos o fórmulas que fijan y estabilizan los comportamientos y las conductas para transformarlos o diseñarlos a la medida de las necesidades del mundo globalizado. Su producto es el entrenamiento del alma individual para producir un sujeto al que Han (2012) ha denominado "sujeto de rendimiento". Un sujeto que adopta la lógica empresarial como la única válida para el manejo de su vida.

Sin embargo, como reguladora de las relaciones sociales, la vigilancia contemporánea no solo es un medio de control. También genera confianza y seguridad para las transacciones sociales. Esto hace que aumenten los costos relacionados con la resistencia, pues, aunque hay navegadores y motores de búsqueda que dificultan el rastreo o eliminan los rastros de visitas o conversaciones, hemos automatizado muchas de las actividades cotidianas (pagos de facturas, compras, uso de redes sociales tradicionales como Facebook, Instagram, WhatsApp o Twitter, etc.) sin prestar demasiada atención al rastreo o uso posterior de los datos. Además, según Koskela (2006), hay cierta fascinación voyerista en ver y, recíprocamente, cierto embeleso exhibicionista en ser visto. La simple idea de la vigilancia evoca 
curiosidad, deseo, agresión, culpa y, sobre todo, miedo. Emociones que interactúan en los ensueños dramáticos de ver y ser visto, de ocultamiento y autoexposición, ataque y defensa, seducción y tentación.

El deseo de lidiar con lo desconocido es el fondo social que justifica los adelantos en las tecnologías de la vigilancia, no solo en asuntos policiales, sino de mercado y de Gobierno. La reducción de la incertidumbre ha sido y será un legítimo deseo humano. Sin embargo, vale la pena preguntarse por los efectos no intencionales o los daños colaterales que las nuevas tecnologías de la vigilancia ocasionarán a la vida íntima, a la vida social y a los modos de interacción comunitarias, deliberar sobre ellos y poder tomar decisiones razonadas respecto de aquello que emerge de lo que se ha dado en llamar sociedad de la vigilancia.

\section{Referencias}

Arango, M. R. (2018). Las cadenas de la subjetividad: un estudio de los dispositivos de control de la vida social. Medellín, Colombia: Universidad Eafit.

Barrero, A. (2018, febrero 7). El Apple Watch rompe récords de ventas. Recuperado de https://www.lavanguardia.com/tecnologia/20180207/44590269290/apple-watch-ventas.html

Bauman, Z. (2006). Vida líquida (A. Santos Mosquera, trad.). Barcelona, España: Paidós.

Bauman, Z. (2007). Libertad. Buenos Aires, Argentina: Losada.

Bauman, Z. y Lyon, D. (2013). Vigilancia líquida (A. Capel Tatjer, trad.). Barcelona, España: Paidós.

Bichieri, C. (2019). Nadar en contra de la corriente: cómo unos pocos pueden cambiar los comportamientos de toda una sociedad (A. Casas, trad.). Bogotá, Colombia: Paidós. 
Bigo, D. (2008). Security: A field left fallow. En M. Dillon \& A. W. Neal (Eds.), Foucault on politics, security and war (pp. 93-114). Londres, RU: Palgrave Macmillan.

Bogard, W. (2006). Surveillance assemblages and lines of flight. En D. Lyon (Ed.), Theorizing Surveillance: The panopticon and beyond (pp.97122). Cullompton, RU: Willan Publishing.

Chou, H.-T. G. \& Edge, N. (2012). "They are happier and having better lives than I am": The impact of using Facebook on perceptions of others' lives. Cyberpsychology, Behavior, and Social Networking, 15(2), 117-121.DOI: https://doi.org/10.1089/cyber.2011.0324

Coviello, L., Sohn, Y., Kramer, A. D., Marlow, C., Franceschetti, M., Christakis, N. A. \& Fowler, J. H. (2014). Detecting emotional contagion in massive social networks. PloS one, 9(3), e90315. DOI: https:// doi.org/10.1371/journal.pone.0090315

Debord, G. (2002). La sociedad del espectáculo (J. L. Pardo, trad.). Valencia, España: Pre-Textos.

Deleuze, G. (1995). Conversaciones, 1972-1990. Valencia, España: Pre-Textos.

Drouin, M., Miller, D., Wehle, S. M. J. \& Hernandez, E. (2016). Why do people lie online? "Because everyone lies on the internet". Computers in Human Behavior, 64, 134-142. DOI: https://doi. org/10.1016/j.chb.2016.06.052

Elmer, G. \& Opel, A. (2006). Pre-empting panoptic surveillance: Surviving the inevitable war on terror . En D. Lyon (Ed.), Theorizing Surveillance: The panopticon and beyond (pp. 139-159). Cullompton, RU: Willan Publishing.

Foucault, M. (1989). Vigilar y castigar: nacimiento de la prisión. Ciudad de México, México: Siglo XXI. 
Foucault, M. (2007). Historia de la sexualidad. Vol. I: La voluntad de saber (31. ${ }^{\mathrm{a}}$ ed.). Ciudad de México, México: Siglo XXI.

Genosko, G. \& Thompson, S. (2006). Tense theory: Temporalities of surveillance. En D. Lyon (Ed.), Theorizing Surveillance: The panopticon and beyond (pp. 123-138). Cullompton, RU: Willan Publishing.

Haggerty, K.D. (2006). Tear down the walls: On demolishing the panopticon. En D. Lyon (Ed.), Theorizing Surveillance: The panopticon and beyond (pp. 23-45). Cullompton, RU: Willan Publishing.

Han, B.-C. (2012). La sociedad del cansancio (A. S. Arregi, trad.). Barcelona, España: Herder.

Han, B.-C. (2014). Psicopolítica: neoliberalismo y nuevas técnicas de poder. Barcelona, España: Herder.

Han, B.-C. (2018). Buen entretenimiento. Barcelona, España: Herder.

Hartmans, A. (2017, diciembre 25). People still aren't buying smartwatches - and it's only going to get worse. Recuperado de https://www. businessinsider.com/smartwatch-usage-declining-emarketer-report-says-2017-12

Koskela, H. (2006). 'The other side of surveillance': Webcams, power and agency. En D. Lyon (Ed.), Theorizing Surveillance: The panopticon and beyond (pp. 163-181). Cullompton, RU: Willan Publishing.

Lipovetsky, G. (1998). La era del vacío: ensayos sobre el individualismo contemporáneo. Barcelona, España: Anagrama.

Los, M. (2006). Looking into the future: Surveillance, globalization and the totalitarian potential. En D. Lyon (Ed.), Theorizing Surveillance: The panopticon and beyond (pp. 69-94). Cullompton, RU: Willan Publishing. 
Lyon, D. (1995). El ojo electrónico: el auge de la sociedad de la vigilancia (J. Alborés, trad.). Madrid, España: Alianza.

Lyon, D. (2003). Introduction. En D. Lyon (Ed.), Surveillance as social sorting: Privacy, risk, and digital discrimination (pp. 1-9). Londres, RU: Routledge.

Lyon, D. (2006). The search for surveillance theories. En Lyon (Ed.), Theorizing Surveillance: The panopticon and beyond (pp. 3-20). Cullompton, RU: Willan Publishing.

Manjarrés, E. (2017). Facebook en la sociedad de control: aplicación simultánea del panóptico y del sinóptico en un dispositivo de vigilancia y control (Tesis de maestría, Universidad Eafit, Medellín, Colombia).

Mayer-Schönberger, V. \& Cukier, K. (2013). Big data: la revolución de los datos masivos (A. J. I. Jurado, trad.). Madrid, España: Turner.

Nielsen, J. (2006, octubre 9). The 90-9-1 Rule for Participation Inequality in Social Media and Online Communities. Recuperado de https:// www.nngroup.com/articles/participation-inequality/

Norris, C. (2003). From personal to digital: CCTV, the panopticon, and the technological mediation of suspicion and social control. En D. Lyon (Ed.), Surveillance as social sorting: Privacy, risk, and digital discrimination (pp. 249-281). Londres, RU: Routledge.

Orwell, G. (1949/2018). 1984 (3. a ed.). Barcelona, España: Penguin Random House.

Whitaker, R. (1999). El fin de la privacidad: cómo la vigilancia total se está convirtiendo en realidad. Barcelona, España: Paidós. 